\title{
Accurate Variable Control System for Boom Sprayer Based on Auxiliary Antidrift System
}

\author{
Jun Fu $\mathbb{D}^{1,2}$ Chao Chen, ${ }^{1,2}$ Rongqiang Zhao $\mathbb{D}^{1,2}$ and Luquan Ren ${ }^{1,2}$ \\ ${ }^{1}$ Key Laboratory of Bionic Engineering, Ministry of Education, Jilin University, Changchun, China \\ ${ }^{2}$ College of Biological and Agricultural Engineering, Jilin University, Changchun 130022, China
}

Correspondence should be addressed to Rongqiang Zhao; sharmmi@126.com

Received 5 November 2019; Accepted 18 December 2019; Published 11 January 2020

Guest Editor: Yuan Li

Copyright (C) 2020 Jun Fu et al. This is an open access article distributed under the Creative Commons Attribution License, which permits unrestricted use, distribution, and reproduction in any medium, provided the original work is properly cited.

\begin{abstract}
Control accuracy significantly affects the performances of boom sprayer. In this study, we develop a precise autocontrol technology based on the vehicle speed feedback. We utilize the auxiliary antidrift system of wind-curtain type air flow and the variable spraying control system for adaptive fertilizing and online measuring of working conditions. Experimental results demonstrate that the variable spraying control system could keep the speed error less than $3 \%$. The air flow significantly improves the penetration of spraying, decreases the fog drip, and increases the pesticide utility. Benefitting from the auxiliary air flow, the average utility of pesticide is improved from $26.76 \%$ to $37.98 \%$. Additionally, the speed feedback control reduces the consumption of pesticide by more than $12 \%$
\end{abstract}

\section{Introduction}

As an important technology for agriculture, spraying has attracted increasing attention over the world [1-4]. Boom sprayers can be employed for pesticide to reduce the threat of diseases, insect pests, and weeds of crops. Till now, a set of studies have been carried out to improve the performance of spraying, including reduction of pesticide consumption, decreasing the size of fog drip, and increasing the penetration [5-7]. In general, precise plant protection machineries are driven by electromechanical hydraulic systems and they are controlled through photoelectric systems. As the development of the remote sensing (RS), the geography information systems (GIS), and the global positioning systems (GPS), which are always referred to as the $3 \mathrm{~S}$ technology, the air flow antidrift technologies have been widely used on the boom sprayer for higher control accuracy. Specifically, a set of parameters are collected online to achieve intelligent control of spraying, for instance, pressure and flow of pesticide [8-14]. In [8], a variable spraying control system is proposed to recognize weed from pea seedling images such that the intelligent weeding is realized. In [9], the authors develop a suspended air-assisted system to improve the performance of boom sprayer. In [11], a variable spraying system is proposed by using multiple combined nozzles for spraying. In addition, the geographic information technology and higher pressure electrostatic spraying technology are also applied for intelligent spraying. For the control theory, various methods have been proposed to improve the accuracy $[15,16]$, the speed $[17,18]$, and the robustness $[19,20]$.

However, the study of boom sprayer still faces considerable challenges. First, the accuracy of control system is not satisfied. Second, the reduction of pesticide requires further improvement. To address these problems, in this study, we develop a novel variable control system boom sprayer based on the wind-curtain air flow and online inspection of working condition. We realize the online supervision of key parameters of a spraying system, including the spraying pipeline pressure, the flow of pesticide, the residue of pesticide in tank, and the traveling speed. The key parameters of work quality, such as the working conditions of boom, are also considered. Benefitting from the wind-curtain air flow antidrift technology, the penetration of spraying is improved, 
and the drifting of fog drip is increased. Hence, the pesticide consumption is significantly reduced.

The remainder of this paper is organized as follows: Section 2 describes the outline of the developed variable control system. Section 3 introduces the proposed control method. Section 4 provides the developed hardware and software. Section 5 presents the experimental results and analysis. Section 6 draws the conclusion.

\section{Outline of the Developed Variable Control System}

In this section, we first describe the used variable boom sprayer in this study. Next, we briefly introduce the outline of the developed system.

2.1. Used Variable Boom Sprayer. The used variable boom sprayer in this study is introduced as follows: The least power is $45 \mathrm{~kW}$. The rated capacity of pesticide tank is $3000 \mathrm{~L}$. The spraying amplitude is $24 \mathrm{~m}$. The wheel track is $1800 \mathrm{~mm}$ to $2200 \mathrm{~mm}$ that is adjustable. The ground clearance of nozzle is $0.5 \mathrm{~m}$ to $2.0 \mathrm{~m}$. The rated spraying pressure is $0.3 \mathrm{MPa}$ to $0.5 \mathrm{MPa}$. The adjusted range of the amount of pesticide application is $150 \mathrm{hm}^{2}$ to $750 \mathrm{~L} / \mathrm{hm}^{2}$. The control accuracy of pesticide application is $\pm 5 \%$. The work speed is $6 \mathrm{~km} / \mathrm{h}$ to $10 \mathrm{~km} / \mathrm{h}$. The productivity is set to be larger than $12 \mathrm{hm}^{2} / \mathrm{h}$. The overall size of the used mechanism is $5800 \mathrm{~mm} \times 3750 \mathrm{~mm} \times 3600 \mathrm{~mm}$. As shown in Figure 1, the variable control system is composed of the wind curtain air flow antidrift system and the variable spraying control system.

2.2. Outline of the Developed System. By online monitoring of the working conditions, the variable spraying control system is able to adaptively adjust the amount of sprayed pesticide based on the traveling speed of the sprayer. For the proposed control method, the setting value of the amount of used pesticide for a unit area is first input into the control system. Then the control system carries out the monitored travelling speed to compute the current amount of pesticide for a unit area. Next, we compare the measured value with the setting value. If the difference between the compared values exceeds the threshold, the control system will wake the actuator to automatically adjust the spraying pressure. Based on this feedback, the actual amount of pesticide used for a unit area, i.e., the pesticide flow, can be close to the expected value. Therefore, the precise spraying is achieved.

With the on-broad advanced reduced instruction set computing machine (ARM) controller, the work speed, pipeline flow, and pressure can be acquired by sensors through the controller area network bus (CAN BUS). The data input by users are combined to compute the required variables which are sent to the drive circuit. As a result, the speed regulation of the DC motor of the electrical ball valve is realized. The outline of the developed system is presented in Figure 2.

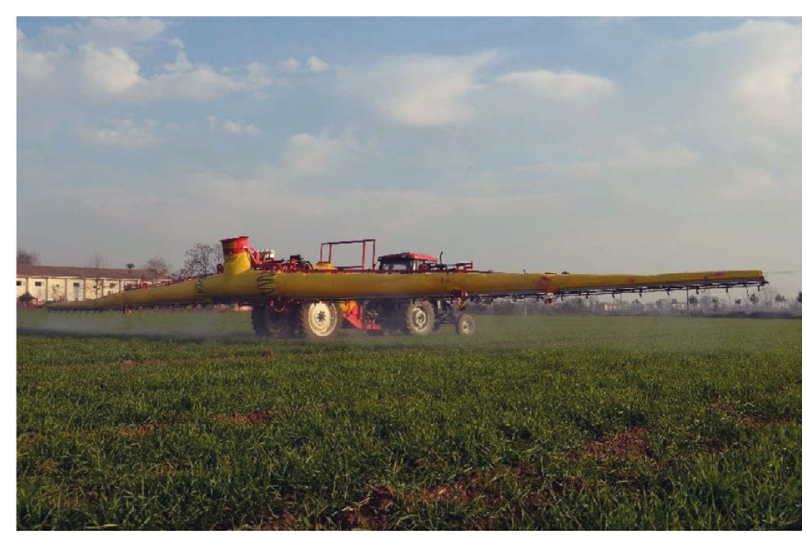

Figure 1: The used variable boom sprayer.

\section{Proposed Control Method}

The outline of the proposed control method is shown in Figure 3. The system input parameters are the machine forward speed value, and the output result is the flow value.

Assume that the entire farmland is divided into a set of areas, and the pesticide consumption per hectare $R\left(\mathrm{~L} / \mathrm{hm}^{2}\right)$ is given by

$$
R=60000 \frac{\int Q d t}{S}
$$

where $Q$ denotes the instantaneous flow of nozzle $(\mathrm{L} / \mathrm{min})$ and $S$ denotes the actual spraying area $\left(\mathrm{m}^{2}\right)$ that is given by

$$
S=D \int v d t
$$

where $D$ and $v$ represent the width of the actual spraying area (m) and the work speed (m/s), respectively. Combining (1) and (2), we have

$$
R=\frac{60000}{D} \int \frac{Q}{v} d t .
$$

Therefore, we can estimate $R$ in advance empirically. If $D$ is given, the nozzle flow $Q$ is regarded to be proportional to the instantaneous work speed $v$ at a certain moment. To ensure the variable $R$ reaches the expected value, $Q$ and $v$ should be kept proportional during the spraying.

For better atomization, we control the regular atomization cone to be $110^{\circ}$ by using the dual sector nozzle. The nozzle interval is equivalent to be or more than $50 \mathrm{~cm}$ based on the requirement of the nozzle. The height of boom is generally $50 \mathrm{~cm}$ higher than the top of the crop. Combining the above analysis, the width of the actual spraying area $D(\mathrm{~m})$ can be expressed as

$$
D=(m-1) L+2 h \tan \alpha
$$

where $m$ denotes the quantity of nozzles, $L$ denotes the distance of adjacent nozzles, $h$ represents the ground clearance of nozzle, and $\alpha$ is the spraying angle of nozzle. For 


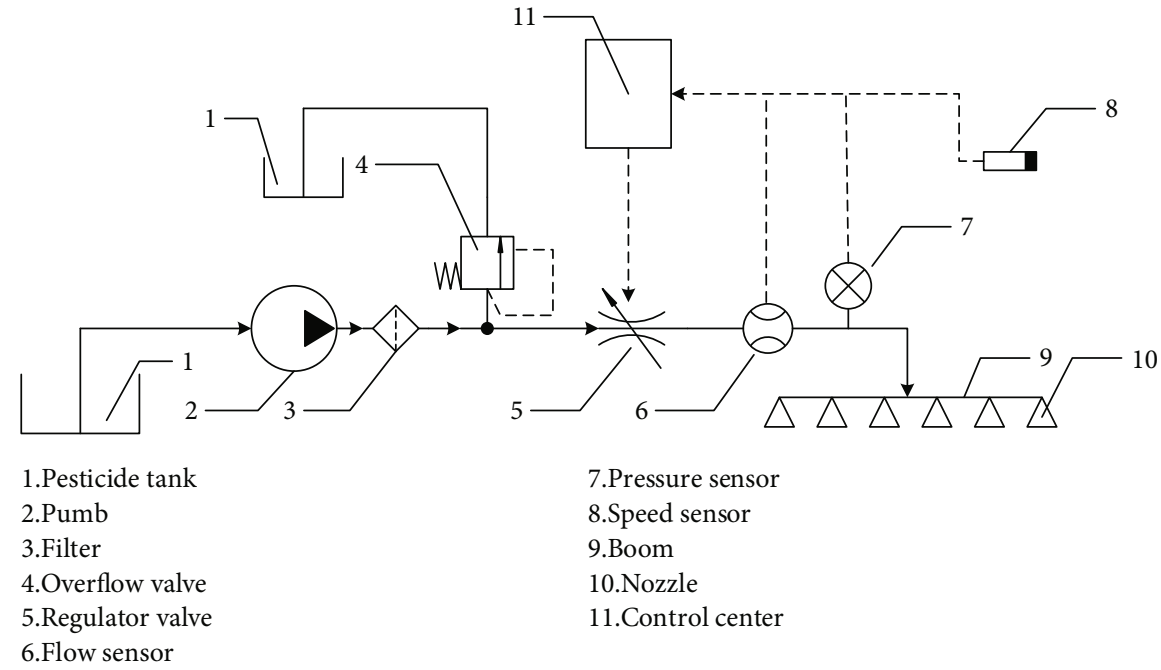

FIgURE 2: Outline of the developed system.

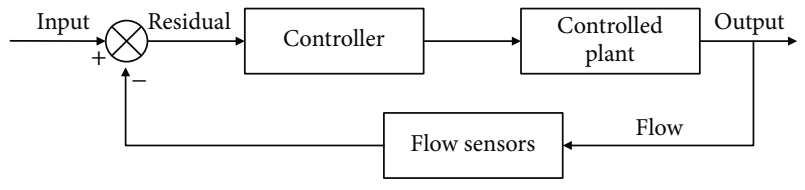

Figure 3: Outline of the closed loop.

the propsed closed-loop control method, when the current flow is close to the target flow, the controller employs the pulse width modulation method to reduce the speed of the ball valve motor. The purpose is to reduce the overshoot caused by the delay and reduce the adjustment time, which is equivalent to reducing the delay characteristics of the ball valve.

We use the PWM mode for motor control that is introduced as follows: The ARM controller first calculates the current feedback value according to the sensor acquisition information and then makes a judgment based on the feedback value. Finally, the controller sends a corresponding function code FC (function code). The function code is used to control the polarity, on-off, and size of the ball valve input voltage, thereby changing the DC motor motion state and finally changing the ball valve opening degree. The FC can be expressed as

$$
\mathrm{FC}=\left\{\begin{array}{l}
1, C_{1}<\frac{\left|Q_{b}-Q_{a}\right|}{\left|Q_{a}\right|}, \\
0, C_{0}<\frac{\left|Q_{b}-Q_{a}\right|}{\left|Q_{a}\right|}<C_{1}, \\
-1,0<\frac{\left|Q_{b}-Q_{a}\right|}{\left|Q_{a}\right|}<C_{0},
\end{array}\right.
$$

where $Q_{a}$ and $Q_{b}$ denoted the theoretical value and the measured value of $Q$, respectively, $C_{0}$ is the maximum allowable error of the system, and $C_{1}$ is obtained through the experiments. For convenience of description, $C_{1}$ is hereinafter regarded as a critical value, $C$. If $F C=1$, set the full speed mode such that the ball valve motor rotates at full speed. If $\mathrm{FC}=0$, set the PWM mode such that the ball valve motor speed is reduced. The ARM calculates the duty cycle in real time according to the designed method. If $\mathrm{FC}=-1$, The regulating valve does not move such that the flux is fixed.

The online flow is essential to the variable spraying. Specifically, it relates to the flow in the unit area and the accumulative flow. Therefore, it is necessary to control the speed of the regulator valve motor. In other words, when the motor is closed to the expected angle, the PWM works to slow down the speed. For the close loop control, the controller uses the pulse width modulation to decrease the rpm of the ball valve motor when the current flow is close to the expected value. It is aimed at reducing the overmodulation due to the delaying. The less modulation duration means the less delaying of the ball valve. The motor rpm downward curve is given by the antitrigonometric function, expressed as

$$
f(x)=\frac{1}{2 \tan ^{-1} 10}\left[\tan ^{-1}(10-20 x)+\tan ^{-1} 10\right] .
$$

We discretize the curve to obtain the duty ratio that is used to regulate the motor speed. As presented in Figure 4, it can be noted that the rpm drops rapidly as the percentage of time increases. We then calculate the residual between the integration of the discretized curve and that of the original curve, expressed as

$$
\frac{\int_{0}^{1} v_{\text {red }}(t) d t}{\int_{0}^{1} v_{\text {blue }}(t) d t}=0.9996
$$

Therefore, the error of the discretizing operation is only $0.04 \%$, which can be ignored in practical. The duty ratio from the output of the drive circuit is directly selected from the discretized curve. 


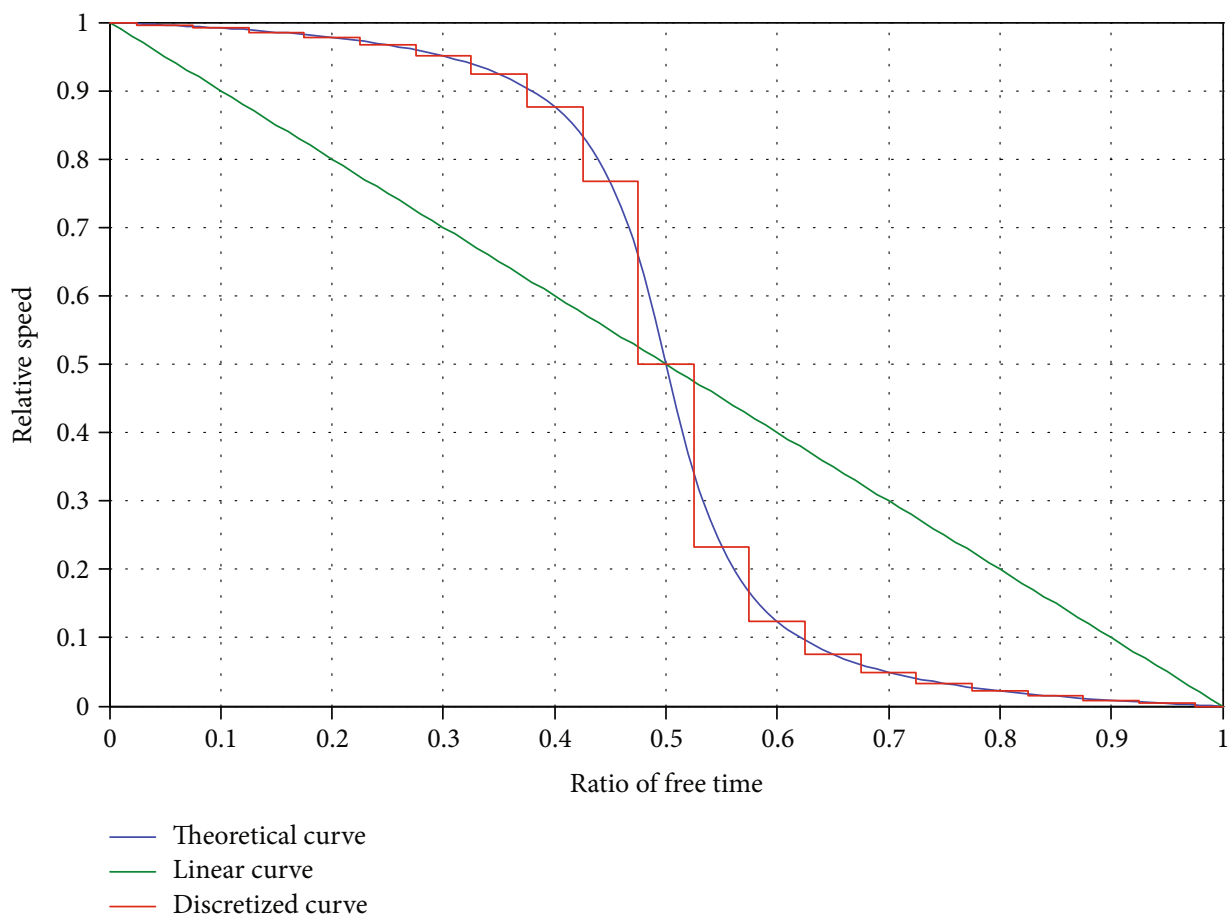

FIGURE 4: Speed reduction curves.

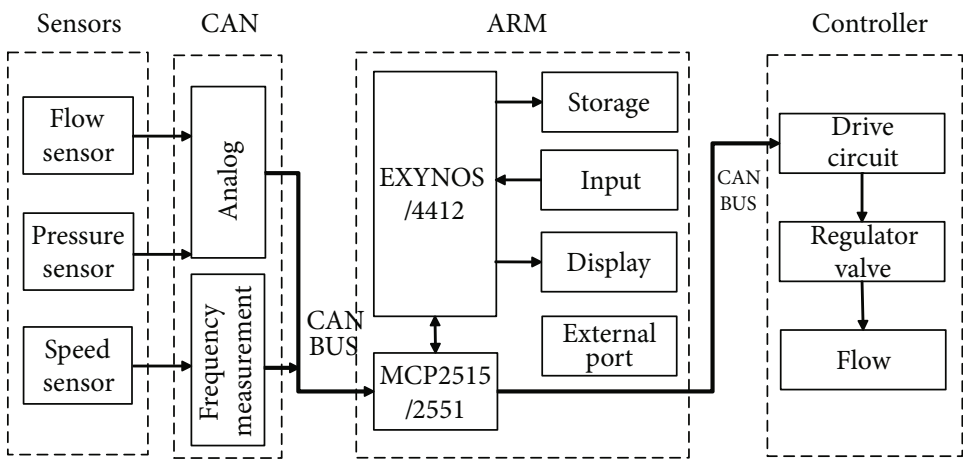

FIGURE 5: Speed reduction curves.

\section{Hardware and Software of the Developed System}

In this section, we introduce the hardware and software of the developed system, respectively.

4.1. Hardware. Our hardware system is mainly composed of the on-broad ARM controller, the CAN collection module, the wheel rpm detection module, the real-time flow detection module, the pressure detection module, the flow regulator, the power supply, etc. As shown in Figure 5, the central processing unit is Samsung Exynos 4412 ARM. The base is mounted with the CAN receiving and sending ports, input and output ports of touchscreen, the peripheral collecting device, the changeover circuit, the drive module, the electrical ball valve, etc. Consisting of PIC18F2580 microcontroller and VNH3SP30 chips, the drive circuit is used to drive the regulator valve motor and to control the $\mathrm{rpm}$ and direction of the motor.

The Exynos 4412 chip has low power consumption. The Coretex-A9 Quad Core chips have enriched sources, including the $1.4 \mathrm{GHz}$ main frequency, 64 -digit/128-digit bus, and $2 \mathrm{~GB}$ of memory. There are ten functional modules, summarized as follows:

(1) Storage and document modules

(2) Multicore computer unit

(3) Multimedia unit

(4) BUS

(5) Communication port

(6) Management of power supply modules 


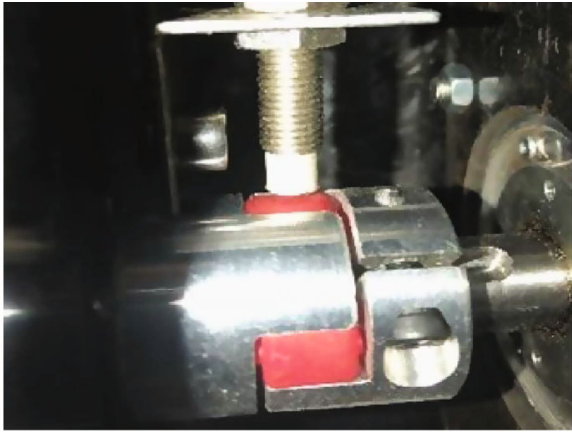

(a)

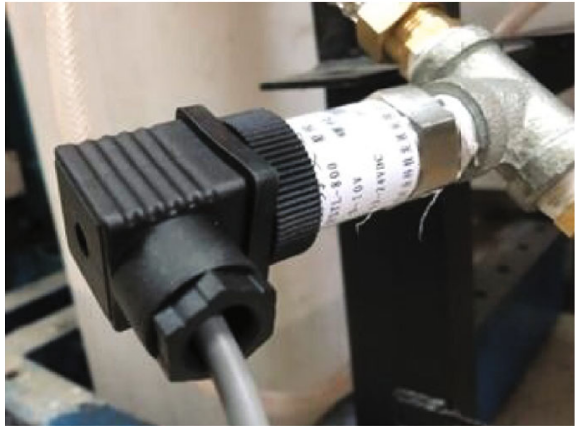

(c)

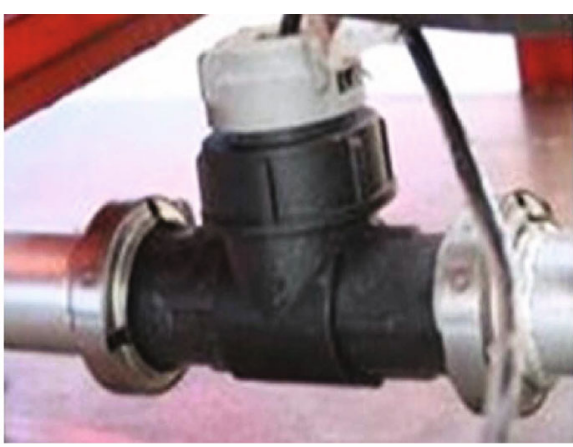

(b)

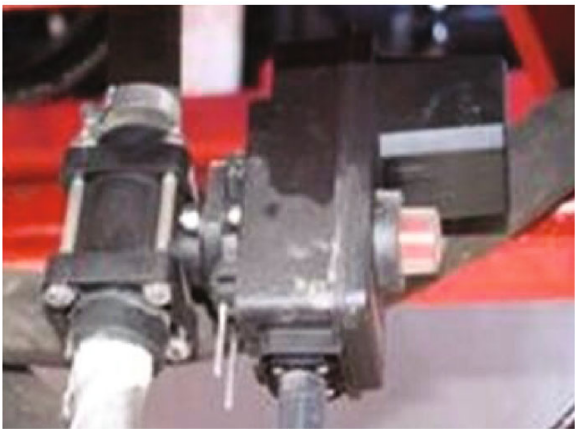

(d)

FIgURE 6: Sensors and controllers: (a) speed sensor, (b) flow sensor, (c) pressure sensor, and (d) flow valve.

(7) System unit

(8) Safety module

(9) Audio module

(10) GPS/GLONASS subsystem

Each detection system and regulation unit are integrated on the development board as a node that is connected to the BUS with the CAN controller and receiver. The CAN network sends the parameters in terms of the online wheel speed, the flow, and the pressure. The speed detection sensor utilizes the hall element to obtain the pulse frequency to calculate the work speed. The real-time flow monitor is in fact the turbine flow sensor. When the tested fluid flows through the sensor vanes, the vanes begin to rotate, periodically changing the reluctance of the pipeline. The pressure monitor uses the diffusion-silicon pressure transmitter to measure the pipeline pressure ranging from 0 to $1 \mathrm{MPa}$, with the power supply voltage at $12 \sim 36 \mathrm{VDC}$, the precision at $\pm 0.50 \%$, and the two-wire output voltage signal from 0 to $5 \mathrm{~V}$. The output signal is connected through the port to the CAN analog collection module. The real-time flow is controlled with a flow control valve. In addition, the flow regulator is composed of the electric regulator valve, the drive circuit, and the power supply. The electric regulator valve controls the fluid flowing from the valve body. The drive circuit of the regulator valve is employed to drive the DC motor of the regulator valve and to control the speed and directions of the DC motor. The power supply is $12 \mathrm{VDC}$. The installations are shown in Figure 6.
4.2. Software. The host computer is developed by using the Qt SDK. As shown in Figure 7, the working conditions of the sprayer are displayed in the left side of the window, including the pipeline pressure, the forward-movement speed, and the current amount of pesticide consumption. In the middle of the window, the flow-time curve created by the "Qt Widgets for Technical Applications" (QWT) is provided. The current time and the input of the sprayer parameters are presented in the right side of the window from top to bottom, respectively. The internally calculated parameters are dependent on the quantity of nozzles, the height of boom, and the nozzle interval. The functional buttons are provided in the bottom of the window, including “+," “-," "Auto, ” "Manual, " and "Start/Stop," which can be used to online adjust the parameters for better working conditions.

The host and slave computers communicated the network via the CAN BUS. As there is no CAN BUS port on the PC, the CAN is first converted to USB, and then the PC is connected with the CAN BUS network of the slave computer. The network communication between host and slave computers is realized by using the Secure SHell FileSystem (SSHFS).

\section{Experimental Results}

In this section, we present the experimental results and analysis. First, we conduct the experiments to verify the developed variable control method based on different working speeds. Second, we verify the reduction of pesticide consumption. 


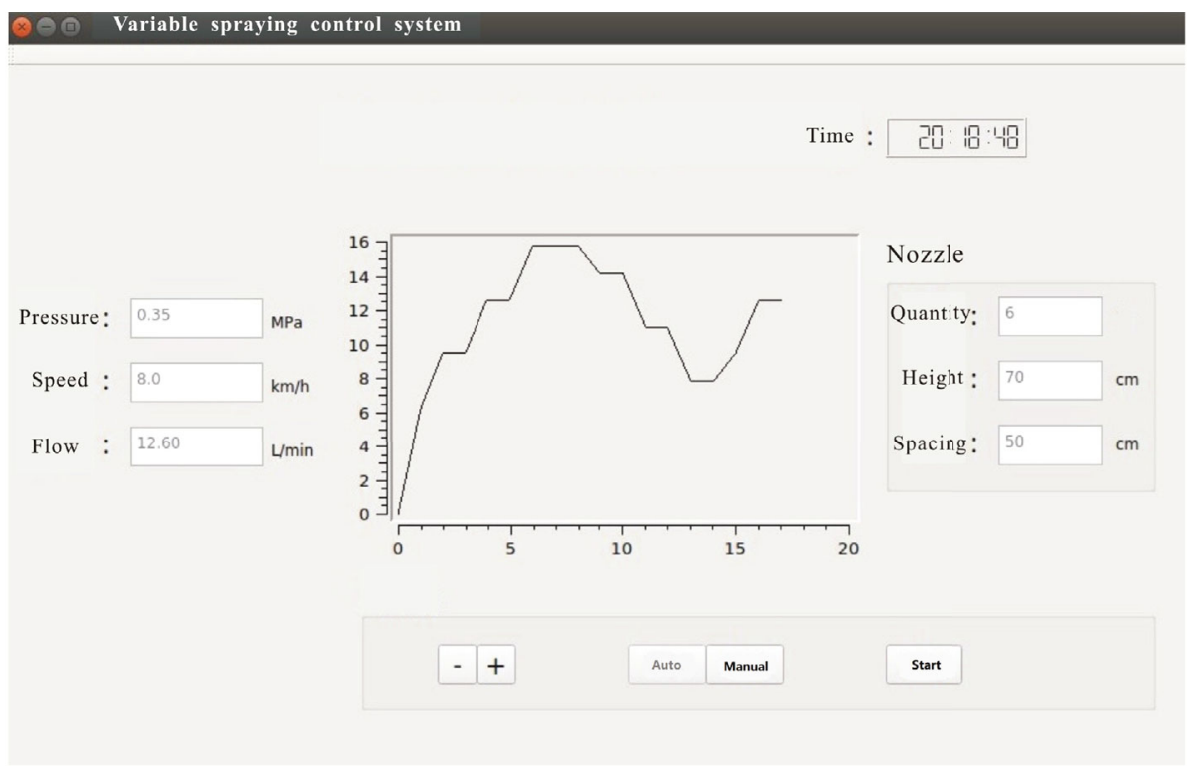

FIgURE 7: Software of the developed system.

TABLE 1: Comparison between the actual speed and the speed of control system.

\begin{tabular}{lcc}
\hline Actual speed $(\mathrm{km} / \mathrm{h})$ & $\begin{array}{c}\text { Speed of control } \\
\text { system }(\mathrm{km} / \mathrm{h})\end{array}$ & Relative error $(\%)$ \\
\hline 4.55 & 4.42 & 2.9 \\
6.64 & 6.79 & 2.3 \\
7.21 & 7.36 & 2.1 \\
8.56 & 8.32 & 2.3 \\
10.85 & 10.96 & 1.0 \\
19.54 & 19.85 & 1.6 \\
\hline
\end{tabular}

First, we considered the accuracy of the speed control. We conducted the experiments in the farming field and the grazing field from a national agricultural hi-tech demonstration zone. We set different working speeds during the experiments. For each value of speed, the actual speed and the speed of the control system were recorded. We then calculated the relative tolerance between them. The results are presented in Table 1 . The results demonstrate that for different speeds the relative tolerances based on all set values are less than 3\%. Thus, the accuracy of the monitoring system is satisfied.

Next, we focused on the accuracy of spraying. Similarly, we selected different working speeds and set different expected consumptions of pesticide per area. For each set of parameters, we recorded the theoretical amount of spraying and the actual amount of spraying and calculated the spraying error. The results are provided in Tables 2 and 3. It can be noted that, benefitting from the proposed approach, the spraying pressure can be tuned automatically, such that the spraying error is controlled less than $5 \%$, regardless of the parameter settings. The results indicate that the accuracy of working speed control and the spraying pressure control could meet the requirements of agriculture production. The results presented in Table 3 demonstrate the speed feedback control reduces the pesticide consumption by $12.7 \%$ to $15.2 \%$ for different experimental settings.

Finally, we performed the experiments to verify the reduction of pesticide consumption by using the proposed control system. This part of experiments was conducted in the corn field in Shaanxi farming and grazing farm. The line spacing is $70 \mathrm{~cm}$ and the corn spacing is $20 \mathrm{~cm}$. The leaf area index (LAI) is 1.78. The environment for the experiments is described as follows: The wind speed is $2 \sim 2.5 \mathrm{~m} / \mathrm{s}$. The temperature is $30^{\circ} \mathrm{C}$. The used pesticide is the rhodamine $\mathrm{B}$ (fluorescent tracer) with the concentration of $0.1 \%$. Two conditions are considered for the variable boom sprayer, working with and without the auxiliary air flow, which are shown in Figures 8 and 9, respectively. For the variable boom sprayer, the spraying pressure is $0.4 \mathrm{MPa}$. The working speed is set to $6.7 \mathrm{~km} / \mathrm{h}$, and the air flow speed is $15 \mathrm{~m} / \mathrm{s}$.

To evaluate the efficiency of the spraying of the pesticide, we defined the "pesticide utility," denoted by $P$, as follows,

$$
P=\frac{A_{1}}{A_{2}},
$$

where $A_{1}$ represents the amount of pesticide deposited on the crop and $A_{2}$ denotes the amount of consumed pesticide from the sprayer. The results are presented in Table 4 .

From the results, we can note that the proposed system significantly increases the pesticide utility. It is mainly because the wind-curtain air flow makes the pesticide more penetrative and reduces the drifting of drips. With the auxiliary air flow, the average utility of pesticide for different experimental settings is $37.98 \%$. On the other hand, the results based on the system without the auxiliary air flow are only $26.76 \%$. Therefore, we believe the proposed variable boom sprayer is able to reduce the consumption of spraying 
TABLE 2: Results on the accuracy of spraying.

\begin{tabular}{|c|c|c|c|c|c|c|}
\hline Nozzle model & $\begin{array}{l}\text { Set value of pesticide } \\
\text { consumption }\left(\mathrm{L} / \mathrm{hm}^{2}\right)\end{array}$ & $\begin{array}{c}\text { Working } \\
\text { speed }(\mathrm{km} / \mathrm{h})\end{array}$ & $\begin{array}{l}\text { Theoretical amount } \\
\text { of spraying }(\mathrm{L} / \mathrm{min})\end{array}$ & $\begin{array}{c}\text { Actual amount } \\
\text { of spraying }(\mathrm{L} / \mathrm{min})\end{array}$ & $\begin{array}{c}\text { Measured } \\
\text { pressure }(\mathrm{MPa})\end{array}$ & $\begin{array}{c}\text { Relative spraying } \\
\text { error }(\%)\end{array}$ \\
\hline \multirow{4}{*}{ ST110-2 (yellow) } & \multirow{2}{*}{174} & 6.79 & 23.63 & 22.45 & 0.31 & 5.0 \\
\hline & & 7.46 & 26.0 & 24.65 & 0.35 & 5.2 \\
\hline & \multirow{2}{*}{290} & 6.79 & 39.38 & 40.75 & 0.78 & 3.47 \\
\hline & & 7.46 & 43.27 & 43.75 & 0.95 & 1.1 \\
\hline \multirow{4}{*}{ ST110-4 (red) } & \multirow{2}{*}{400} & 6.79 & 54.32 & 54.54 & 0.52 & 0.4 \\
\hline & & 7.46 & 59.68 & 60.01 & 0.63 & 0.6 \\
\hline & \multirow{2}{*}{550} & 3.39 & 37.29 & 37.68 & 0.35 & 1.1 \\
\hline & & 4.07 & 44.72 & 45.33 & 0.55 & 1.3 \\
\hline \multirow{4}{*}{ ST110-6 (grey) } & \multirow{2}{*}{673} & 3.39 & 45.63 & 43.65 & 0.37 & 4.3 \\
\hline & & 4.07 & 54.78 & 52.85 & 0.51 & 3.5 \\
\hline & \multirow{2}{*}{750} & 3.39 & 50.85 & 50.75 & 0.48 & 0.2 \\
\hline & & 4.07 & 61.05 & 61.65 & 0.67 & 1.0 \\
\hline
\end{tabular}

TABLE 3: Results on pesticide consumption with the speed feedback.

\begin{tabular}{|c|c|c|c|c|}
\hline $\begin{array}{l}\text { Nozzle } \\
\text { model }\end{array}$ & $\begin{array}{l}\text { Working } \\
\text { speed } \\
(\mathrm{km} / \mathrm{h})\end{array}$ & $\begin{array}{l}\text { Pesticide consump } \\
\qquad\left(\mathrm{L} / \mathrm{hm}^{2}\right) \\
\text { The vehicle speed } \\
\text { feedback }\end{array}$ & ion & $\begin{array}{l}\text { Pesticide } \\
\text { reduction } \\
\quad(\%)\end{array}$ \\
\hline \multirow{2}{*}{$\begin{array}{l}\text { ST110-2 } \\
\text { (yellow) }\end{array}$} & 6 & 281 & 322 & 12.7 \\
\hline & 7 & 287 & 338 & 15.1 \\
\hline \multirow{2}{*}{$\begin{array}{l}\text { ST110-4 } \\
\text { (red) }\end{array}$} & 6 & 548 & 635 & 13.7 \\
\hline & 4 & 543 & 641 & 15.2 \\
\hline \multirow{2}{*}{$\begin{array}{l}\text { ST110-6 } \\
\text { (grey) }\end{array}$} & 3 & 744 & 855 & 13.0 \\
\hline & 4 & 743 & 860 & 13.6 \\
\hline
\end{tabular}

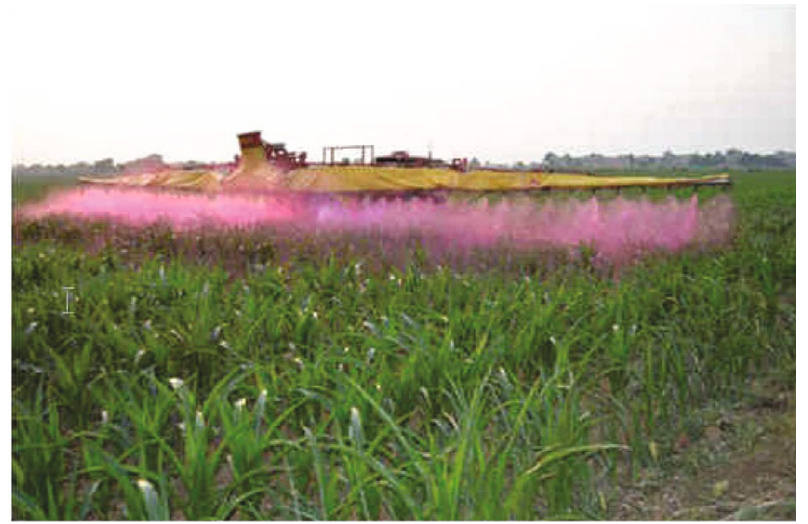

FIgURE 8: Experiment with auxiliary airflow.

pesticide and reduce the environmental pollution by increasing its pesticide utility.

\section{Conclusions}

In this paper, we propose a novel boom sprayer based on the auxiliary antidrift system of wind-curtain type air flow. The developed variable spraying control system achieves adaptive

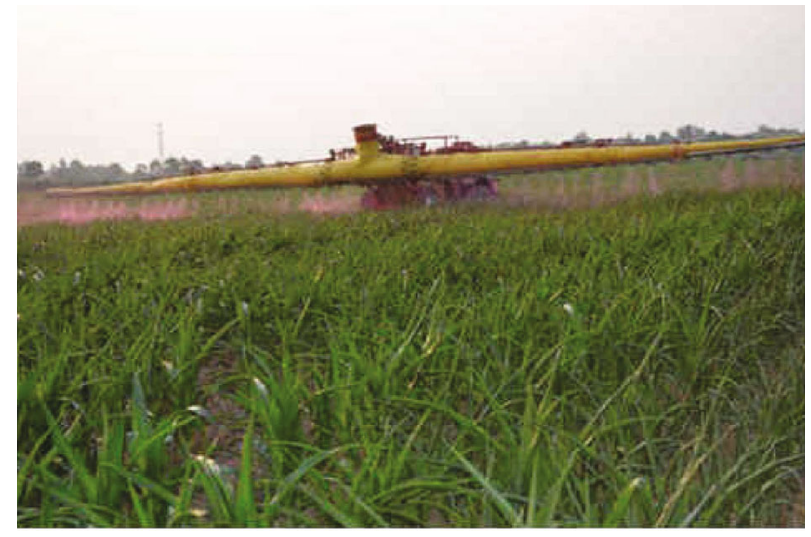

FIGURE 9: Experiment without auxiliary airflow.

TABLE 4: Results on pesticide utilization in maize fields.

\begin{tabular}{lcccc}
\hline Nozzle & $\begin{array}{c}\text { VMD Dv50 } \\
\text { model }\end{array}$ & $\begin{array}{c}\text { Pesticide } \\
\text { consumption } \\
\left(\mu / \mathrm{hm}^{2}\right)\end{array}$ & $\begin{array}{c}\text { Pesticide utility (\%) } \\
\text { With } \\
\text { auxiliary } \\
\text { air flow }\end{array}$ & $\begin{array}{c}\text { Without } \\
\text { auxiliary } \\
\text { air flow }\end{array}$ \\
\hline ST110-02 & 234.2 & 163 & 35.51 & 19.34 \\
ST110-04 & 289.6 & 274 & 36.36 & 26.06 \\
ST110-05 & 337.7 & 355 & 38.13 & 28.46 \\
ST110-06 & 369.8 & 372 & 41.93 & 33.20 \\
$\begin{array}{l}\text { Average } \\
\text { value }\end{array}$ & $/$ & $/$ & 37.98 & 26.76 \\
\hline
\end{tabular}

fertilizing and online measurement of working conditions. By using the developed variable spraying control system, the speed error can be controlled within 3\%. The air flow significantly improves the penetration of spraying, decreases the fog drip, and increases the pesticide utility. Benefitting from the auxiliary air flow, the average utility of pesticide is improved from $26.76 \%$ to $37.98 \%$. Additionally, the speed feedback control reduces the consumption of pesticide by more than $12 \%$. 


\section{Data Availability}

The data used to support the findings of this study are available from the corresponding author upon request.

\section{Conflicts of Interest}

The authors claim no conflicts of interest.

\section{Acknowledgments}

This work was supported by the Scientific and Technological Developing Scheme of Jilin Province under Grant $20190701055 \mathrm{GH}$.

\section{References}

[1] P. C. H. Miller and M. C. B. Ellis, "Effects of formulation on spray nozzle performance for applications from groundbased boom sprayers," Crop Protection, vol. 19, no. 8-10, pp. 609-615, 2000.

[2] B. J. Qiu, R. Yan, J. Ma, X. Guan, and M. Ou, "Research progress analysis of variable rate sprayer technology," Transactions of the Chinese Society for Agricultural Machinery, vol. 46, no. 3, pp. 59-72, 2015.

[3] M. T. Batte and M. R. Ehsani, "The economics of precision guidance with auto-boom control for farmer-owned agricultural sprayers," Computers and Electronics in Agriculture, vol. 53, no. 1, pp. 28-44, 2006.

[4] A. Bayat and M. Itmec, "The current state of sprayer manufacturers in Turkey and some strategies for the future," Scientific Papers-series A-agronomy, vol. 61, no. 2, pp. 105-108, 2018.

[5] Z. DongYan, Y. B. Lan, C. LiPing, W. Xiu, and L. Dong, "Status and future trends of agricultural aerial spraying technology in China," Transactions of the Chinese Society for Agricultural Machinery, vol. 45, no. 10, pp. 53-59, 2014.

[6] D. Nuyttens, M. De Schampheleire, K. Baetens, and B. Sonck, "The influence of operator-controlled variables on spray drift from field crop sprayers," Transactions of the ASABE, vol. 50, no. 4, pp. 1129-1140, 2007.

[7] T. Esau, Q. Zaman, D. Groulx et al., "Economic analysis for smart sprayer application in wild blueberry fields," Precision Agriculture, vol. 17, no. 6, pp. 753-765, 2016.

[8] Z. XiaoLong, X. ZhengChun, Z. NianSheng, and C. ChengMao, "Weed recognition from pea seedling images and variable spraying control system," Transactions of the Chinese Society for Agricultural Machinery, vol. 43, no. 11, pp. 220-225, 2012.

[9] Z. Haiyan, W. Jia, Y. Suzhen, J. Zhenhua, and W. Jinjiang, "Development of 3WQX-1300 type suspended air-assisted boom sprayer," Agricultural Engineering, vol. 4, pp. 67-70, 2011.

[10] M. Yasin, “Air assisted sleeve boom sprayer," Ama-agriculural Mechanization in Asia Africa and Latin America, vol. 43, no. 1, pp. 61-66, 2012.

[11] X. Yanlei, B. Jialin, F. Daping, and Z. Chiyang, "Design and experiment of variable spraying system based on multiple combined nozzles," Transactions of the Chinese Society of Agricultural Engineering, vol. 32, no. 17, pp. 47-54, 2016.

[12] H. C. Foster, B. P. Sperry, D. B. Reynolds, G. R. Kruger, and S. Claussen, "Reducing herbicide particle drift: effect of hooded sprayer and spray quality," Weed Technology, vol. 32, no. 6, pp. 714-721, 2018.

[13] X. Liu, X. Zhang, F. Liu, and M. Weiwe, "Multi-objective dynamic design optimization for air duct of air-assisted boom sprayer based on RVM," Transactions of the Chinese Society for Agricultural Machinery, vol. 41, no. 6, pp. 75-80, 2010.

[14] M. E. Teske and H. W. Thistle, "Technical note: a comparison of single spray path ground boom sprayer deposition patterns," Transactions of the ASABE, vol. 54, no. 5, pp. 15691571, 2011.

[15] B. Zhang, J. Wu, L. Wang, Z. Yu, and P. Fu, "A method to realize accurate dynamic feedforward control of a spray-painting robot for airplane wings," IEEE-ASME Transactions on Mechatronics, vol. 23, no. 3, pp. 1182-1192, 2018.

[16] W. Huang, Y. Zhang, X. Zhang, and G. Sun, “Accurate torque control of interior permanent magnet synchronous machine," IEEE Transactions on Energy Conversion, vol. 29, no. 1, pp. 2937, 2014.

[17] H. Lens, J. Adamy, and D. Domont-Yankulova, "A fast nonlinear control method for linear systems with input saturation," Automatica, vol. 47, no. 4, pp. 857-860, 2011.

[18] M. Van, M. Mavrovouniotis, and S. S. Ge, "An adaptive backstepping nonsingular fast terminal sliding mode control for robust fault tolerant control of robot manipulators," IEEE Transactions on Systems, Man, and Cybernetics: Systems, vol. 49, no. 7, pp. 1448-1458, 2019.

[19] B. Zhu, J. Zhang, M. Suo, L. Chen, Y. Zhang, and S. Li, "Robust stability analysis and controller synthesis for uncertain impulsive positive systems under L1-gain performance," ISA Transactions, vol. 93C, pp. 55-69, 2019.

[20] V. Fakhari, A. Ohadi, and H. A. Talebi, "A robust adaptive control scheme for an active mount using a dynamic engine model," Journal of Vibration and Control, vol. 21, no. 11, pp. 2223-2245, 2013. 


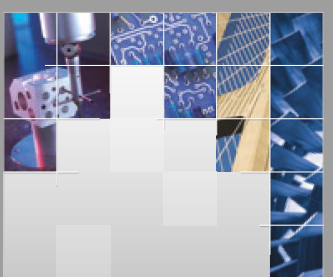

\section{Enfincering}
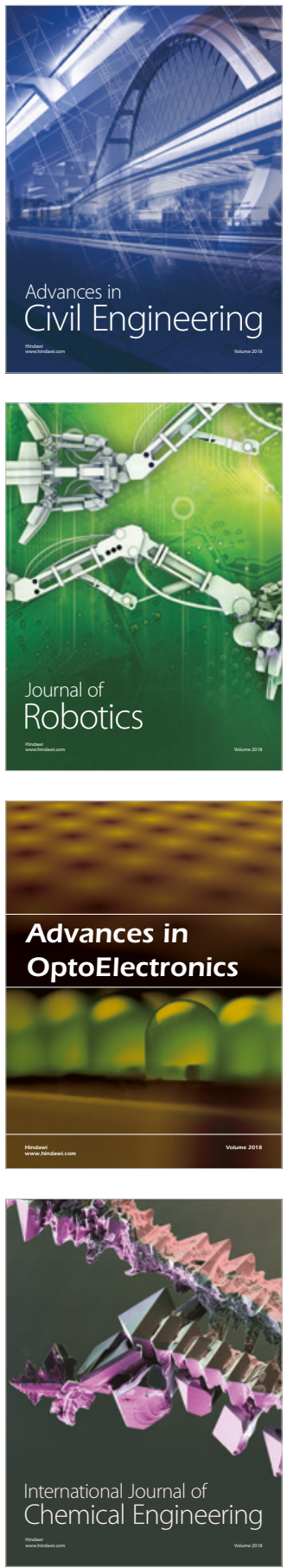

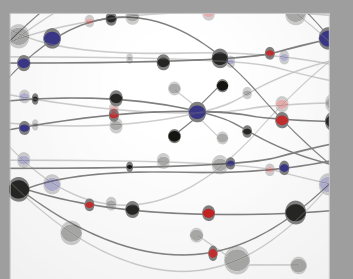

\section{Rotating \\ Machinery}

The Scientific World Journal

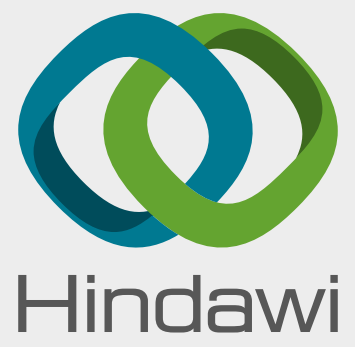

Submit your manuscripts at

www.hindawi.com
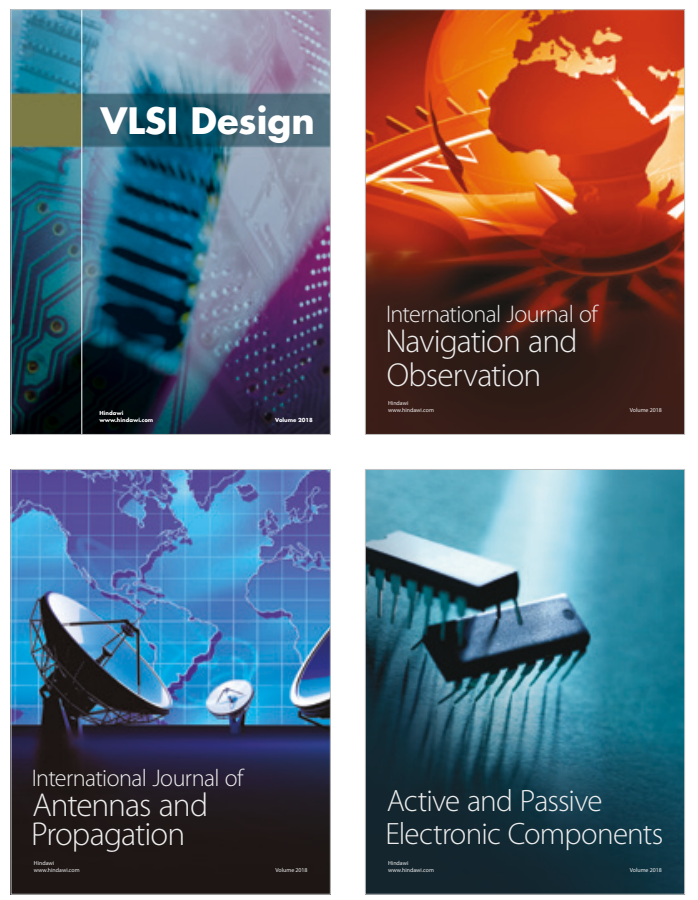
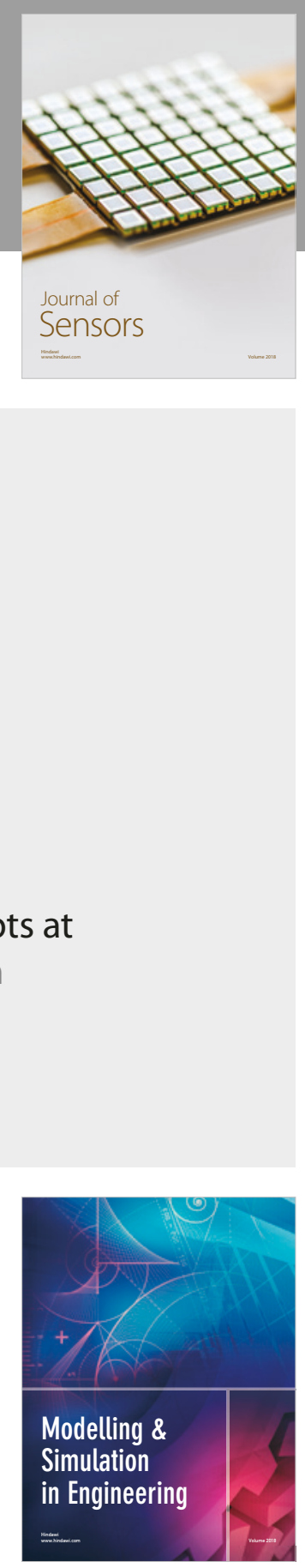

\section{Advances \\ Multimedia}
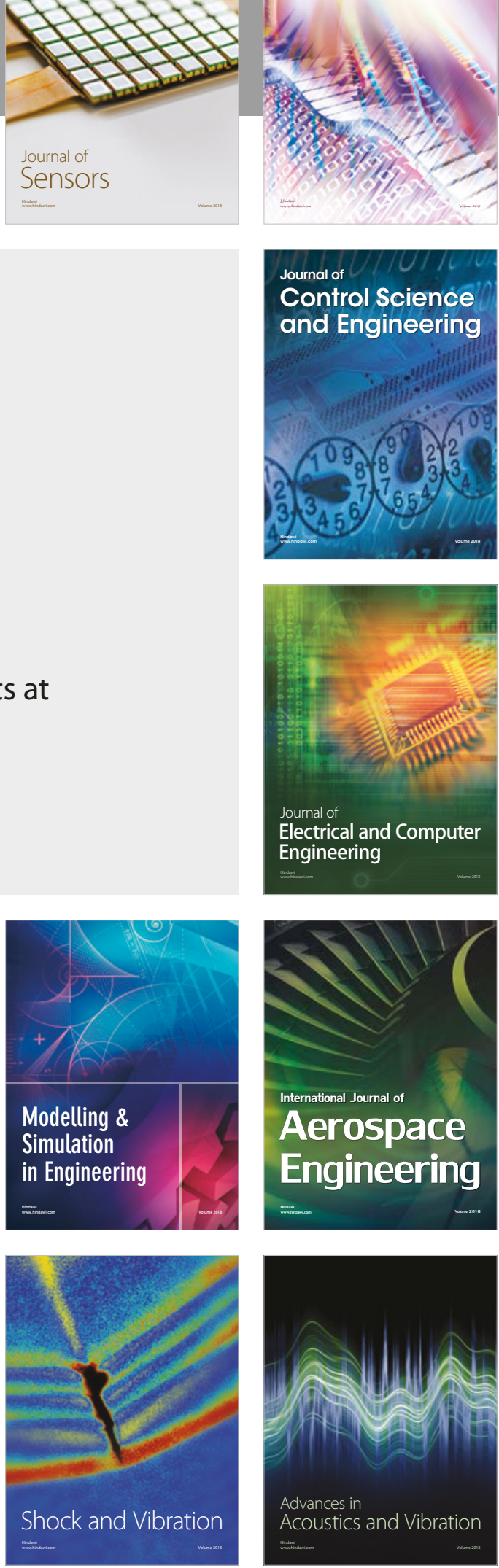